\title{
Weight loss and bone mineral density in obese adults: a longitudinal analysis of the influence of very low energy diets
}

\author{
Palak Choksi ${ }^{1 *}$ (D), Amy Rothberg ${ }^{1,4}$, Andrew Kraftson ${ }^{1}$, Nicole Miller ${ }^{1}$, Katherine Zurales ${ }^{1}$, Charles Burant ${ }^{1,2,4}$, \\ Catherine Van Poznak ${ }^{1}$ and Mark Peterson ${ }^{3}$
}

\begin{abstract}
Background: The long-term effect of weight reduction on skeletal health is not well understood. The purpose of this study was to examine the impact of an intensive medical weight loss intervention using very low energy diet (VLED) ( $800 \mathrm{cal} /$ day) that result in significant changes in body weight, on total body bone mineral density (BMD) over 2 years.

Methods: We examined the impact of VLED-induced weight loss on BMD and FFM (Fat-free Mass) after 3-6 months and again while in weight maintenance at 2 years in 49 subjects. The effects of absolute and relative rate of weight reduction assessed by change in weight in kilograms were assessed using general linear modeling, with baseline BMD (or FFM) as a covariate, and age, sex and changes in body weight as primary model predictors.

Results: At the end of 2 years, the average weight loss was greater for men (weight: $23.51 \pm 12.5 \mathrm{~kg}$ ) than women (weight: $16.8 \pm 19.2 \mathrm{~kg})$ and BMD loss was greater among women $\left(0.03 \pm 0.04 \mathrm{~g} / \mathrm{cm}^{2} \mathrm{vs} 0.01 \pm 0.04 \mathrm{~g} / \mathrm{cm}^{2}\right)($ all $p<0.05)$. After adjusting for baseline BMD, age, and sex, there was a small but significant association between total weight loss and 2-year BMD $\left(\beta=-0.001 \mathrm{~g} / \mathrm{cm}^{2} ; p=0.01\right)$. Similarly, there was a significant independent association between total weight loss and 2 -year FFM $(\beta=-116.5 \mathrm{~g} ; p<0.01)$.
\end{abstract}

Conclusions: Despite significant weight loss with VLED, there was only a small loss is BMD.

Keywords: Bone density, DXA, Weight loss, Obesity, Very low energy diets

\section{Background}

Among Americans aged 20 years and older, the prevalence of obesity is approximately $35 \%$. Obesity contributes to morbidity and mortality [1]. By 2030, the total healthcare costs attributed to obesity may reach as much as $\$ 957$ billion [2]. Despite addressing many of the associated co-morbid conditions of obesity, little attention has been paid to the potentially long-term effects of weight change on bone health. Although bone loss is known to occur following bariatric surgeries, little is known about the effects of diet-induced weight loss, and specifically weight loss achieved by a very-low energy diets (VLED).

\footnotetext{
* Correspondence: palak@med.umich.edu

${ }^{1}$ Department of Internal Medicine, University of Michigan, 24 Frank Lloyd Wright Dr, Ann Arbor, Ml 48106, USA

Full list of author information is available at the end of the article
}

Bone strength adapts to meet demands of musculoskeletal loading, and therefore, body weight is one of the strongest predictors of bone mineral density (BMD) [3]. Mechanical stimulation of bone leads to osteoblast proliferation, and conversely, reduction in mechanical loading can cause an increase in bone turnover [4]. Lean body mass and fat mass are both independent positive determinants of bone mass, and although BMD may be higher among obese individuals, BMD per unit of BMI is lower and not necessarily protective from the risk of fractures [5,6]. Excess weight due to adiposity is detrimental to bone, and therefore, obesity itself may predict fractures [7]. Clinical opinions and research pertaining to the impact of weight loss on the bone has been inconclusive. Short-term, longitudinal studies have shown that weight loss achieved through energy restriction can result in an increase in bone turnover that is sustained 
even during weight maintenance $[8,9]$. In addition to BMD, bone turnover markers are thought to predict fracture risk [10]. The long-term effects of VLED on $\mathrm{BMD}$ and bone turnover markers following weight loss are yet to be identified.

Very-low energy diets are those that contain $\leq 800 \mathrm{cal}$ per day, and provide essential daily nutritional requirements. VLEDs have become increasing popular in medically-supervised weight reduction programs for short durations (e.g., 8-12 weeks), with typical weight losses of $1.5-2.5 \mathrm{~kg} /$ week, or $18-20 \%$ after $8-12$ weeks $[11,12]$. When incorporated as part of an intensive, behavioral lifestyle program, the majority of VLED induced weight loss can be sustained long-term [11]. This approach offers a less costly, less invasive and practical alternative to endoluminal and surgical approaches.

Due to the growing obesity prevalence, dietary strategies that restrict calories have shown utility for improving metabolic health and health-related quality-of-life [13]. However, the long-term effect of weight reduction on skeletal health is not well understood. The primary objective of our study was to determine the longitudinal association between VLED-induced weight loss on whole body BMD. In addition, we examined whether weight loss influenced an important bone turnover marker.

\section{Methods}

\section{Design}

We included adults who were enrolled in and completed a 2-year weight management program. All participants provided written informed consent and the study protocol was reviewed and approved by the University of Michigan Institutional Review Board. The trial is registered at Clinicaltrials.gov (NCT02043457). The University of Michigan Weight Management Program (MWMP) is a 2-year, multidisciplinary, multicomponent, obesity management program, and has been previously described in detail [13]. Briefly, participants consume a VLED in the form of total meal replacements and are asked to increase physical activity from low to moderate intensity for $40 \mathrm{~min}$ per day. Each meal replacement shake contained $160 \mathrm{kcal}, 14 \mathrm{~g}$ of protein, $23 \mathrm{~g}$ of carbohydrates and were fortified with calcium, multiple vitamins including vitamin D. In addition, all participants were prescribed a multivitamin and Vitamin D3 2000 IU daily. After 3 to 6 months, participants were transitioned to regular foods and asked to increase physical activity to moderate-vigorous for 40-60 min per day. Thereafter, the intervention was focused on behavioral and pharmacologic strategies to prevent weight regain. An individualized diet plan comprised of approximately 1200$1800 \mathrm{kcal} /$ day was designed, implemented and titrated to maintain the individual's reduced weight. A registered dietitian evaluated participants weekly for one month and then monthly for the remainder of the two years. The physician saw participants monthly for three months and then every three months for the rest of the two years. Participants underwent whole body DXA scanning on a (GE Lunar prodigy Advance; Control serial number 070401531487; control model number 7635) by a trained research technician at baseline, after transition to weight maintenance at approximately 6 months, and at the end of the 2-year program. In addition, serum for bone turnover markers was collected to assess the impact of weight loss on bone resorption.

\section{Study participants}

The program was designed for obese (BMI $\geq 30 \mathrm{~kg} / \mathrm{m}^{2}$ [or $\geq 27 \mathrm{~kg} / \mathrm{m}^{2}$ in Asian Americans]) adults $\geq 18$ years of age. Participants in the program were representative of the demographic of southeastern Michigan, primarily Non-Hispanic whites, educated and employed. The clinic was founded on the principles of the National Heart Lung and Blood Institute (NHLBI) report that addressed long-term weight management for obese individuals (available at https://www.ncbi.nlm.nih.gov/ pubmed/24961824) [14]. Participants were excluded if they had unstable psychiatric disorders requiring frequent changes in medications, cancer within the last 5 years (other than non-melanomatous skin cancers), active gallbladder or chronic kidney disease with eGFR $\leq 35 \mathrm{ml} / \mathrm{min}$, and/or prior bariatric surgery.

Demographic, clinical and metabolic data were collected and entered into a database. This data included participant's anthropometric, co-morbid health conditions, medications, laboratory, biopsychosocial and imaging data that was updated after each visit.

\section{Primary outcomes}

Morphological Assessment: Whole body BMD, total adiposity assessed as total fat mass (FM) and percent body fat $(\% \mathrm{BF})$ were measured by dual-energy X-ray absorptiometry in the Michigan Clinical Research Unit. Determination of FFM was performed for the whole body as a part of the DXA scan. DXA allows for precise assessment of FFM, comprised of fat-free soft tissue and BMD.

Biochemical analyses: Serum cross-linked C-telopeptide (CTX) was collected at baseline, after weight loss between 3 and 6 months, and at the end of the 2-year program for $n=$ 25 subjects (selected based on available fasting samples). All blood samples were collected into $(2 \mathrm{ml}$ tubes containing EDTA following a $12 \mathrm{~h}$ overnight fast to reduce variation associated with circadian rhythms and feeding [15]. The tests were analyzed at the University of Michigan, Michigan Diabetes Research Center (MDRC) Chemistry laboratory. Serum CTX levels were measured by enzyme-linked immunosorbent assay (ELISA). CTX assessments were done in 
duplicate and all assays were performed in a single run to eliminate interassay variability. The detection limits of this assay were $25-800 \mathrm{ng} / \mathrm{ml}$, and inter and intraassay precision (Coefficients of variation) for CTX assays were $<15 \%$ ).

\section{Statistical analysis}

Descriptive statistics were used to explore the distribution, central tendency, and variation of each measurement, with an emphasis on graphical methods such as histograms, scatterplots, and boxplots. Descriptive statistics for all demographic and morphologic characteristics were reported at baseline, after short-term weight loss, and at the 2-year time point, as change from baseline. Multiple linear regression analyses with post-intervention outcomes as the dependent variable were used to assess the role of weight loss on change in total body BMD and FFM. All models included baseline morphologic characteristics for muscle, BMD and FFM. For the primary aim, age and weight loss were included as continuous predictors of 2-year BMD and FFM. Several interaction terms were tested to determine the mediating effect of age and sex, on changes in muscle, BMD and FFM. Regression assumptions were checked and appropriate transformations (e.g., log) performed if necessary.

For the sub-analysis, we used a multiple linear regression approach to evaluate the association between changes in body weight, BMD, FFM and changes in serum CTX. Due to the smaller sample of adults with complete morphological and serum data $(n=25)$, models included only age as a covariate, and a change score for body weight, BMD, FFM as predictors of change in serum CTX.

\section{Results}

Forty-nine participants completed both the induction and maintenance phase and had complete DXA scans available at baseline, at 3-6 months and at the end of 2 years. At the end of two years, all participants had significant changes in body weight, mean $(-20.8 \pm 11.2 \mathrm{~kg})$, $\%$ FM $(-6.7 \pm 6.0 \%)$, FFM $(-3.45 \pm 3.41 \mathrm{~kg}$, ), and BMD $\left(-0.02 \pm 0.04 \mathrm{~g} / \mathrm{cm}^{2}\right)($ all $p<0.05)$ Descriptive characteristics of participants stratified by sex are presented in Table 1. The decline in BMD was similar for both men and women; however, a statistically significant loss occurred in BMD among women only.

At two years, the mean weight reduction was greater for men than women; however, change in absolute BMD was greater among women $(p<0.05)$. In multivariable analyses shown in Table 2, after adjusting for age, sex, and baseline BMD, we found that the total weight lost at the end of 2 years was associated with a small but statistically significant loss in BMD at 2-years. There was a $0.001 \mathrm{~g} / \mathrm{cm}^{2} \mathrm{de}-$ crease in 2-year BMD per kilogram weight loss. While men lost more FM, women lost significantly more \%FFM than men. Figure 1 shows the changes in \% body weight, body fat, BMD and FFM from baseline to 2 years in men and women. In addition, there was a significant independent association between total weight lost and 2-year FFM $(\beta=-116.5 \mathrm{~g} ; p<0.01)$. Figure 2 includes partial residual scatter plot revealing the correlations between relative changes in body weight and relative changes in BMD (a) and FFM (b), controlling for age and sex.

In addition, we evaluated the changes in BMD at the end of the intensive phase of weight loss (i.e. after 15\% weight loss). There was a small but statistically significant loss in BMD among women only $(0.02 \pm 0.01 \mathrm{~g} /$ $\left.\mathrm{cm}^{2} ; p<0.001\right)$. In both men and women, the loss in $\mathrm{BMD}$ at the end of the intensive phase was significantly correlated to bone loss at 2 years $(r=0.77 ; p<0.01)$ and $(r=0.33, p<0.05)$ respectively.

In the sub-analyses we evaluated changes in the bone resorption marker, serum CTX and its independent association with changes in body weight, BMD, FFM and \%BF. After adjusting for age, change in \%BF was the only significant predictor of changes in serum CTX ( $\beta=23.56 \mathrm{pg} /$ $\mathrm{mL} ; p=0.04)$.

\section{Discussion}

In our study, participants were involved in a two-year weight management program that included a three-month active weight loss phase utilizing an 800-kcal/day standard VLED. Our results show that VLED-induced weight loss can result in a small reduction in total body BMD and FFM at 2-years. Specifically, we found that for every kilogram of weight loss there was a $0.001 \mathrm{~g} / \mathrm{cm}^{2}$ reduction in BMD and $0.1 \mathrm{~kg}$ decrease in FFM at 2-years, after adjusting for age, sex, and baseline BMD. However, it is important to note that this loss of BMD and FFM may also arise from natural consequences of the aging process, as previously described in numerous studies [16]. Indeed, BMD declined substantially in the late peri-menopause, with an average loss of $0.018-0.010 \mathrm{~g} / \mathrm{cm}^{2} / \mathrm{yr}$. from the spine and hip $(P<0.001$ for both). In post menopause, rates of loss from the spine and hip were 0.022 and $0.013 \mathrm{~g} / \mathrm{cm}^{2} / \mathrm{yr} .(P<0.001)$ [17]. Serum CTX levels increased following the intensive phase and remained stable in the maintenance phase. Neither baseline serum CTX nor changes in CTX levels following weight loss were associated with bone loss.

The effect of weight loss on the bone has been controversial with inconsistent clinical opinions and research findings. In the Dubbo Osteoporosis Epidemiologic study, weight change was found to be an independent predictor of rate of bone loss [18]. Moderate weight reduction (greater than 5\%) can negatively influence BMD especially if achieved purely through calorie restriction $[19,20]$. This was also observed in the LOOK AHEAD study, and while intensive lifestyle interventions resulted in better glycemic control and weight loss, a statistically 
Table 1 Morphological characteristics for men and women at baseline and at 2-years

\begin{tabular}{|c|c|c|c|c|c|c|}
\hline & \multicolumn{2}{|l|}{ Men $(n=29)$} & \multirow[b]{2}{*}{ Mean $\Delta$} & \multicolumn{2}{|l|}{ Women $(n=20)$} & \multirow[b]{2}{*}{ Mean $\Delta$} \\
\hline & Baseline & Year 2 & & Baseline & Year 2 & \\
\hline Age (years) & $51.59(6.91)$ & $53.58(6.89)$ & - & $49.30(7.69)$ & $51.28(7.70)$ & - \\
\hline Body Weight (kg) & $123.68(13.58)$ & $102.56(15.16)$ & $23.51(12.45)^{\dagger \neq}$ & $104.47(16.78)^{*}$ & $89.45(14.10)$ & $16.80(7.60)^{\dagger}$ \\
\hline Body Mass Index $\left(\mathrm{kg} \cdot \mathrm{m}^{-2}\right)$ & $38.58(3.86)$ & $31.94(3.92)$ & $7.39(3.99)^{\dagger}$ & $39.17(4.62)$ & $33.53(3.92)$ & $6.32(2.74)^{\dagger}$ \\
\hline Body Fat (\%) & $41.79(4.41)$ & $32.95(7.22)$ & $8.84(6.53)^{\dagger \neq}$ & $51.45(4.39)^{*}$ & $47.88(5.59)$ & $3.57(3.29)^{\dagger}$ \\
\hline Fat Free Mass (kg) & $72.72(6.95)$ & $69.45(7.55)$ & $3.27(4.01)^{\dagger}$ & $51.26(5.72)^{*}$ & $47.54(6.07)$ & $3.72(2.38)^{\dagger}$ \\
\hline Bone Mineral Density $\left(\mathrm{g} / \mathrm{cm}^{2}\right)$ & $1.37(0.06)$ & $1.36(0.09)$ & $0.01(0.04)$ & $1.27(0.07)^{*}$ & $1.24(0.08)$ & $0.03(0.04)^{\dagger \neq}$ \\
\hline T-score & $1.88(0.77)$ & $1.72(1.07)$ & $0.16(0.56)$ & $1.79(0.84)$ & $1.47(0.99)$ & $0.32(0.53)^{\dagger}$ \\
\hline
\end{tabular}

"Significant difference between men and women at baseline $(p<0.05)$

'Significant difference within sex from baseline to 2 years $(p<0.05)$

${ }^{\ddagger}$ Significant difference between men and women for absolute changes from baseline to 2 years $(p<0.05)$

significant loss in BMD was noted at the total hip and femoral neck [21]. The impact of calorie restriction on BMD is seen in younger individuals as well as premenopausal women therefore suggesting that the mechanism is not solely related to age and the effects of sex steroids $[22,23]$. In middle-aged individuals, weight variability has been shown to increase the risk of hip fractures [24]. However, the long-term impact of calorie restriction on fractures is not known [23, 25]. In recently published data from the LOOK AHEAD study, long term weight loss in overweight and obese adults with type 2 diabetes mellitus was not associated with an increase in overall risk of fractures but maybe associated with an increased risk of frailty fractures [26]. A few other studies evaluating the long-term effects of $>5 \%$ weight reduction did not use severe calorie restricted diets [18, 27, 28]. Due to significant energy restriction, VLEDs induce greater weight loss than moderate calorie restricted diets. Citing the need for further research, a meta-analysis performed by Zibellini et al., found that low calorie or VLED's did not cause a reduction in BMD; however, the majority of studies evaluating the impact of VLEDs on bone loss have been limited to one year [25]. In addition, low energy diets that are supplemented with calcium or high proteins are known to mitigate the rise in bone turnover [29]. In our study, although the changes were statistically significant, the change in BMD was small, and thus may not necessarily be clinically relevant in the short term, or with respect to future fracture risk. We postulate that the loss in BMD was likely attenuated by the macro/ micro-nutrient composition of the meal replacement and adequate vitamin $\mathrm{D}$ and mineral intake and less sedentary behavior.

Bariatric surgery remains the most effective form of treatment for severe obesity and historically, Roux-en-Y gastric bypass (RYGB) procedure was the most commonly performed procedure. Though these surgeries are very effective, the risk of bone loss associated with gastric bypass surgery is well documented [30-33]. Surgical procedures are associated with decreases in bone mass and increases in bone turnover markers [34]. Prospective studies have shown that bone loss following gastric

Table 2 Multiple regression showing the associations between changes in body weight (primary predictor) and BMD and FFM at 2-years (dependent variable), after adjustment for age, sex, and baseline values (ANCOVA)

\begin{tabular}{|c|c|c|c|c|c|c|}
\hline & Model Predictor(s) & $\beta$ & SE & $\mathrm{t}$ & $\operatorname{Pr}>|\mathrm{t}|$ & Adjusted $\mathrm{R}^{2}$ \\
\hline \multirow[t]{6}{*}{ BMD at 2 Years } & & & & & & 0.88 \\
\hline & Intercept & -0.084 & 0.120 & -0.680 & 0.500 & \\
\hline & Age & -0.002 & 0.001 & -2.980 & 0.005 & \\
\hline & Sex & -0.015 & 0.014 & -1.080 & 0.285 & \\
\hline & Baseline BMD & 1.155 & 0.082 & 14.010 & $<0.001$ & \\
\hline & Change in Body Weight & -0.001 & 0.001 & -2.460 & 0.017 & \\
\hline \multirow[t]{6}{*}{ FFM at 2 Years } & & & & & & 0.94 \\
\hline & Intercept & 5.790 & 6.780 & 0.860 & 0.397 & \\
\hline & Age & -0.052 & 0.066 & -0.790 & 0.435 & \\
\hline & Sex & -2.420 & 1.880 & -1.290 & 0.205 & \\
\hline & Baseline FFM & 0.950 & 0.074 & 12.770 & $<0.001$ & \\
\hline & Change in Body Weight & -0.117 & 0.045 & -2.620 & 0.012 & \\
\hline
\end{tabular}




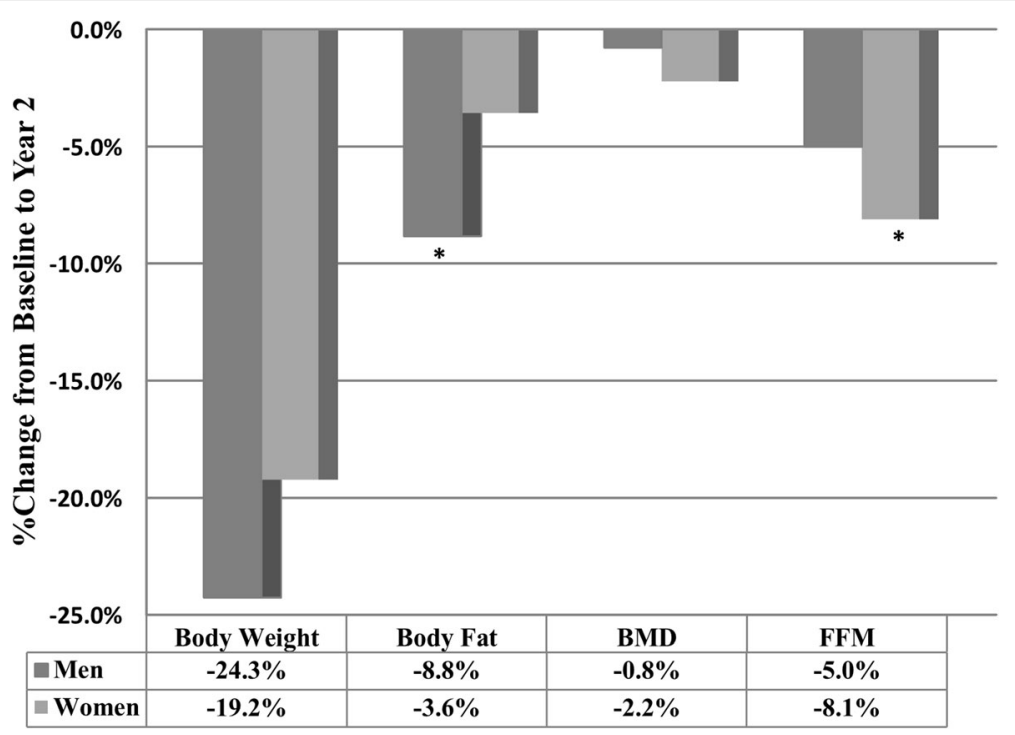

Fig. 1 Relative change in body weight, body fat, BMD and fat free mass from baseline to 2 years in men and women

bypass preferentially affects the hip [32, 35]. Of the various bariatric procedures, sleeve gastrectomy is likely associated with less bone loss than RYGB although the studies are small and more data are needed [36]. We postulate that the derangements in calcium and Vitamin $\mathrm{D}$ absorption are likely to play a greater role in bone loss after surgical procedures. VLEDs may therefore represent a safer, non-invasive alternative to weight loss without the negative impact on bone.

Evidence pertaining to the long-term impact of weight loss on bone turnover is lacking. Some studies have shown low bone turnover in obesity while others have contrary findings [37, 38]. Following bariatric surgery,
Balsa et al. showed an increase in bone turnover markers [39]. In our study, we did not find a correlation between serum CTX and BMD.

\section{Limitations}

In this study, DXA imaging at one year was not available. With this information, we would have been able to assess the sequential changes in BMD in individuals whose weight remained stable and those who experienced weight cycling. In addition, we looked at the total body BMD rather than routinely used sites to assess fragility such as the lumbar spine, femoral neck or hip, and this may result in under diagnosis of osteoporosis [40].
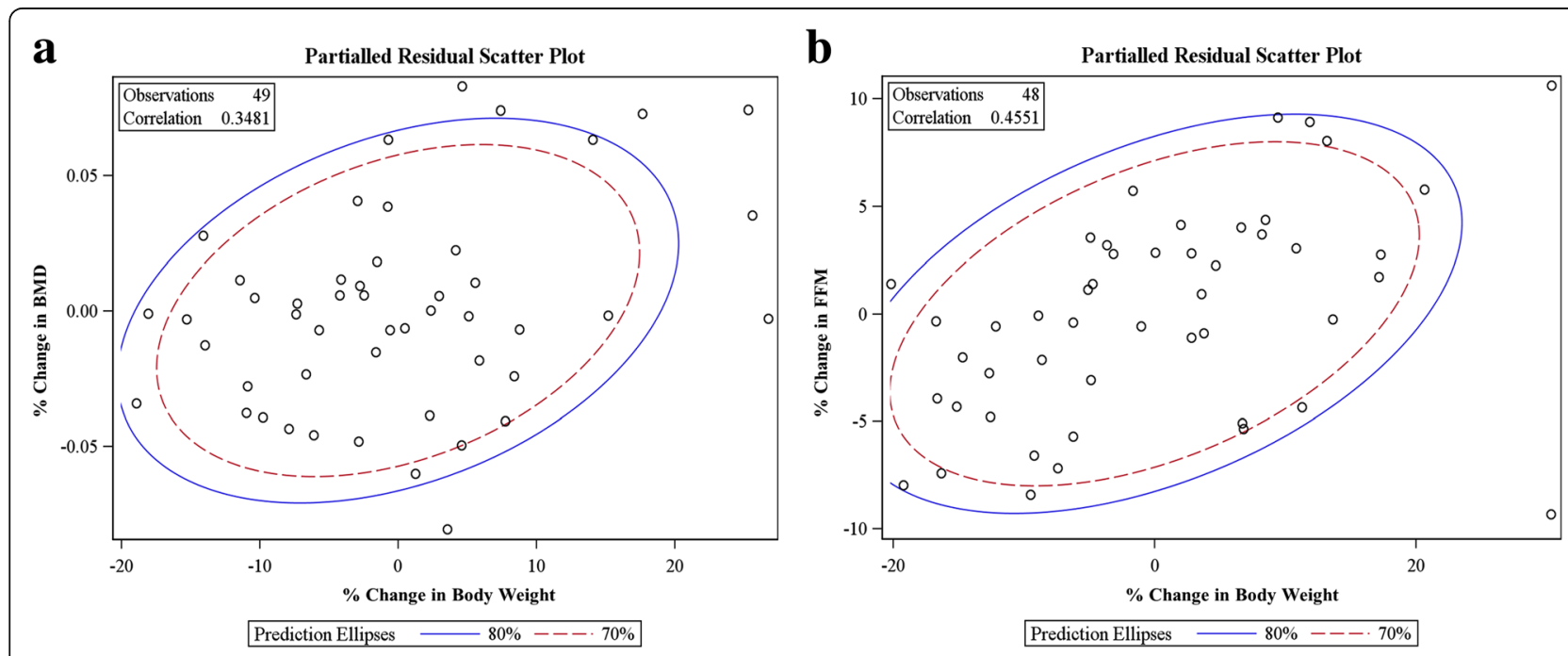

Fig. 2 Partial residual scatter plot revealing the correlations between relative changes in body weight and relative changes in BMD (a) and FFM (b), controlling for age and sex 
Although the utility of DXA in obese individuals is debatable, DXA remains the gold standard and the only available test for measuring BMD in clinical practice [41]. In addition, whether changes in total body water with these diets affects fat and fat-free mass assessments via DXA remains unclear. Our sample size for subgroup analyses on bone markers was small, and thus we had to combine men and women. Future larger studies should aim to determine the longitudinal, dimorphic patterns of weight loss and BMD changes, taking into consideration the mediating influence of serum BTM changes. Lastly, although moderate intensity and regular physical activity was prescribed as part of the program, physical activity and participation was self-reported. Since physical activity and exercise are linked with bone health, future efforts are certainly needed to determine if objectively measured exercise during VLED interventions can ameliorate changes in BMD and FFM. Our future studies will prospectively evaluate key variable such as gonadal status, use of bone altering medications and physical activity.

\section{Conclusion}

Obesity has negative effects on bone metabolism and is associated with a number of cardio-metabolic conditions that pose threats to bone health. We have shown absolute weight loss that can impact BMD. Although VLED can promote significant weight loss the decline in BMD is minor with unclear clinical applicability and must be weighed against the myriad of other benefits resulting from weight loss.

\section{Abbreviations}

BMD: Bone Mineral Density; BMI: Body Mass Index; CTX: Serum cross-linked C-Telopeptide; DXA: Dual X-Ray Absorptiometry; FFM: Fat-Free Mass; FM: Fat Mass; VLED: Very Low Energy Diets

\section{Acknowledgements}

The authors would also like to thank Dr. Henry Bone for his useful feedback on the manuscript.

\section{Funding}

The authors would like to acknowledge the University of Michigan Nutrition Obesity Research Center (MNORC: Grant Number DK089503) and the Michigan Center for Diabetes Translational Research (MCDTR: Grant Number P30DK092926) from the National Institute of Diabetes and Digestive and Kidney Diseases, National Institutes of Health.

Additional support was provided by the A. Alfred Taubman Medical Institute and the Robert C. and Veronica Atkins Foundation.

Dr. Choksi was supported by the Michigan Institute for Clinical \& Health Research (MICHR: Port Grant 2UL1TR000433).

Dr. Peterson is funded by the National Institutes of Health (1KO1 HD074706). The funders had no role in the design and conduct of the study; the collection, analysis, and interpretation of the data; or the preparation, review, or approval of the manuscript.

\section{Authors' contributions}

PC: participated in study concept, design, statistical analysis and drafting the manuscript. AR: participated in study concept, design, statistical analysis and drafting the manuscript. AK: Helped in drafting the manuscript. NM and KZ: participated with data collection and reviewed the manuscript. CB and CVP: participated in its design and coordination and helped to draft the manuscript. MP: participated in study concept, design, statistical analysis and drafting the manuscript. All authors read and approved the final manuscript.

\section{Ethics approval and consent to participate}

All participants provided written informed consent and the study protocol was reviewed and approved by the University of Michigan Institutional Review Board. The trial is registered at Clinicaltrials.gov (NCT02043457).

\section{Competing interests}

The authors declare that they have no competing interests.

\section{Publisher's Note}

Springer Nature remains neutral with regard to jurisdictional claims in published maps and institutional affiliations.

\section{Author details}

${ }^{1}$ Department of Internal Medicine, University of Michigan, 24 Frank Lloyd Wright Dr, Ann Arbor, MI 48106, USA. ${ }^{2}$ Molecular and Integrative Physiology, University of Michigan, Ann Arbor, USA. ${ }^{3}$ Department of Physical Medicine and Rehabilitation, University of Michigan, Ann Arbor, USA. ${ }^{4}$ Department of Nutritional Sciences, University of Michigan, Ann Arbor, USA.

Received: 1 March 2018 Accepted: 30 May 2018

Published online: 19 June 2018

\section{References}

1. Flegal KM, Carroll MD, Kit BK, Ogden CL. Prevalence of obesity and trends in the distribution of body mass index among US adults, 1999-2010. JAMA. 2012;307:491-7.

2. Wang CY, McPherson K, Marsh T, Gortmaker SL, Brown M. Health and economic burden of the projected obesity trends in the USA and the UK. Lancet. 2011;378:815-25.

3. Heaney RPAS, Dawson-Highes B. Peak Bone mass. Ost Int. 2000;11:985-1009.

4. Iqbal J, Zaidi M. Molecular regulation of mechanotransduction. Biochem Biophys Res Commun. 2005;328:751-5.

5. Zaidi M, Buettner C, Sun L, lqbal J. Minireview: the link between fat and bone: does mass beget mass? Endocrinology. 2012;153(5):2070-5.

6. Zhu K, Hunter M, James A, Lim EM, Walsh JP. Associations between body mass index, lean and fat body mass and bone mineral density in middleaged Australians: the Busselton healthy ageing study. Bone. 2015;74:146-52.

7. Nielson CM, Srikanth $\mathrm{P}$, Orwoll ES. Obesity and fracture in men and women: an epidemiologic perspective. J Bone Miner Res. 2012;27:1-10.

8. Hinton PS, LeCheminant JD, Smith BK, Rector RS, Donnelly JE. Weight lossinduced alterations in serum markers of bone turnover persist during weight maintenance in obese men and women. J Am Coll Nutr. 2009;28: 565-73.

9. Rector RS, Loethen J, Ruebel M, Thomas TR, Hinton PS. Serum markers of bone turnover are increased by modest weight loss with or without weight-bearing exercise in overweight premenopausal women. Appl Physiol Nutr Metab. 2009;34:933-41.

10. Garnero P, Delmas PD. Contribution of bone mineral density and bone turnover markers to the estimation of risk of osteoporotic fracture in postmenopausal women. J Musculoskelet Neuronal Interact. 2004;4:50-63.

11. Anderson JW, Grant L, Gotthelf L, Stifler LT. Weight loss and long-term follow-up of severely obese individuals treated with an intense behavioral program. Int J Obes. 2007;31:488-93.

12. Rothberg $A E$, McEwen LN, Kraftson AT, Neshewat GM, Fowler CE, Burant CF, Herman WH. The impact of weight loss on health-related quality-of-life: implications for cost-effectiveness analyses. Qual Life Res. 2014;23:1371-6.

13. Rothberg AE, McEwen LN, Kraftson AT, Fowler CE, Herman WH. Very-lowenergy diet for type 2 diabetes: an underutilized therapy? J Diabetes Complicat. 2014;28:506-10.

14. Guidelines (2013) for managing overweight and obesity in adults. Preface to the expert panel report (comprehensive version which includes systematic 
evidence review, evidence statements, and recommendations). Obesity (Silver Spring). 2014;22(Suppl 2):S40.

15. Seibel MJ. Biochemical markers of bone turnover: part I: biochemistry and variability. Clin Biochem Rev. 2005;26:97-122.

16. Cauley JA, Danielson ME, Greendale GA, Finkelstein JS, Chang YF, Lo JC, Crandall CJ, Neer RM, Ruppert K, Meyn L, Prairie BA, Sowers MR. Bone resorption and fracture across the menopausal transition. the Study of Women's Health Across the Nation Menopause. 2012;19:1200-7.

17. Finkelstein JS, Brockwell SE, Mehta V, Greendale GA, Sowers MR, Ettinger B, Lo JC, Johnston JM, Cauley JA, Danielson ME, Neer RM. Bone mineral density changes during the menopause transition in a multiethnic cohort of women. J Clin Endocrinol Metab. 2008;93:861-8.

18. Nguyen TV, Seibel MJ, Eisman JA. Bone loss, physical activity, and weight change in elderly women: the Dubbo osteoporosis epidemiology study. J Bone Miner Res. 1998;13:1458-67.

19. Jensen $L B$, Kollerup $G$, Quaade F, Sorensen $\mathrm{OH}$. Bone minerals changes in obese women during a moderate weight loss with and without calcium supplementation. J Bone Miner Res. 2001;16:141-7.

20. Villareal DT, Fontana L, Weiss EP, Racette SB, Steger-May K, et al. Bone mineral density response to caloric restriction-induced weight loss or exercise-induced weight loss: a randomized controlled trial. Arch Intern Med. 2006;166:2502-10.

21. Schwartz AV, Johnson KC, Kahn SE, Shepherd JA, Nevitt MC, Peters AL, Walkup MP, Hodges A, Williams CC, Bray GA. Effect of 1 year of an intentional weight loss intervention on bone mineral density in type 2 diabetes: results from the Look AHEAD randomized trial. J Bone Miner Res. 2012;27:619-27.

22. Hamilton KC, Fisher G, Roy JL, Gower BA, Hunter GR. The effects of weight loss on relative bone mineral density in premenopausal women. Obesity (Silver Spring). 2013;21:441-8.

23. Villareal DT, Fontana L, Das SK, Redman L, Smith SR, Saltzman E, Bales C, Rochon J, Pieper C, Huang M, Lewis M, Schwartz AV, Group CS. Effect of two-year caloric restriction on bone metabolism and bone mineral density in non-obese younger adults: a randomized clinical trial. J Bone Miner Res. 2016;31:40-51

24. Meyer HE, Tverdal A, Selmer R. Weight variability, weight change and the incidence of hip fracture: a prospective study of 39,000 middle-aged Norwegians. Osteoporos Int. 1998:8:373-8

25. Zibellini J, Seimon RV, Lee CM, Gibson AA, Hsu MS, Shapses SA, Nguyen TV, Sainsbury A. Does diet-induced weight loss lead to bone loss in overweight or obese adults? A systematic review and meta-analysis of clinical trials. J Bone Miner Res. 2015;30(12):2168-78.

26. Johnson KC, Bray GA, Cheskin LJ, Clark JM, Egan CM, Foreyt JP, Garcia KR, Glasser S, Greenway FL, Gregg EW, Hazuda HP, Hergenroeder A, Hill JO, Horton ES, Jakicic JM, Jeffery RW, Kahn SE, Knowler WC, Lewis CE, Miller M, Montez MG, Nathan DM, Patricio JL, Peters AL, Pi-Sunyer X, Pownall HJ, Reboussin D, Redmon JB, Steinberg H, Wadden TA, Wagenknecht LE, Wing RR, Womack CR, Yanovski SZ, Zhang P, Schwartz AV. The effect of intentional weight loss on fracture risk in persons with diabetes: results from the Look AHEAD randomized clinical trial. J Bone Miner Res. 2017; 32(11):2278-87.

27. Ensrud KE, Ewing SK, Stone KL, Cauley JA, Bowman PJ, Cummings SR. Intentional and unintentional weight loss increase bone loss and hip fracture risk in older women. J Am Geriatr Soc. 2003;51:1740-7.

28. Sogaard AJ, Meyer HE, Ahmed LA, Jorgensen L, Bjornerem A, Joakimsen RM, Emaus N. Does recalled dieting increase the risk of non-vertebral osteoporotic fractures? The Tromso study. Osteoporos Int. 2012;23:2835-45.

29. Redman LM, Rood J, Anton SD, Champagne C, Smith SR, Ravussin E. Calorie restriction and bone health in young, overweight individuals. Arch Intern Med. 2008;168:1859-66.

30. Carrasco F, Ruz M, Rojas P, et al. Changes in bone mineral density, body composition and adiponectin levels in morbidly obese patients after bariatric surgery. Obese Surg 2009:41-46.

31. Coates PS, Fernstrom JD, Fernstrom MH, Schauer PR, Greenspan SL. Gastric bypass surgery for morbid obesity leads to an increase in bone turnover and a decrease in bone mass. J Clin Endocrinol Metab. 2004;89:1061-5.

32. Vilarrasa N, San José P, Garcia I, et al. Evaluation of bone mineral density loss in morbidly obese women after gastric bypass: 3-year follow-up. Obes Surg. 2011;21:465-72.
33. von Mach MA, Stoeckli R, Bilz S, Kraenzlin M, Langer I, Keller U. Changes in bone mineral content after surgical treatment of morbid obesity. Metabolism. 2004;53:918-21.

34. Rodríguez-Carmona Y, López-Alavez FJ, González-Garay AG, Solís-Galicia C, Meléndez G, Serralde-Zúñiga AE. Bone mineral density after bariatric surgery. A systematic review. Int J Surg. 2014;12:976-82.

35. Fleischer J, Stein EM, Bessler M, Della Badia M, Restuccia N, Olivero-Rivera L, McMahon DJ, Silverberg SJ. The decline in hip bone density after gastric bypass surgery is associated with extent of weight loss. J Clin Endocrinol Metab. 2008;93:3735-40.

36. Nogues X, Goday A, Pena MJ, Benaiges D, de Ramon M, Crous X, Vial M, Pera M, Grande L, Diez-Perez A, Ramon JM. Bone mass loss after sleeve gastrectomy: a prospective comparative study with gastric bypass. Cir Esp. 2010;88:103-9

37. Cifuentes M, López-Alavez FJ, Lewis RD et al. Bone turnover and body weight relationships differ in normal-weight compared to heavier postmenopausal women. Osteoporos Int. 2003;14(2):116-22.

38. Ostrowska Z, Zwirska-Korczala K, Bunter B et al. Assessment of bone metabolism in obese women. Endocr Regul 1998; 32.

39. Balsa JA, Botella-Carretero Jl, Peromingo R, Caballero C, Munoz-Malo T, Villafruela JJ, Arrieta F, Zamarron I, Vazquez C. Chronic increase of bone turnover markers after biliopancreatic diversion is related to secondary hyperparathyroidism and weight loss. Relation with bone mineral density. Obes Surg. 2010;20:468-73.

40. Graat-Verboom L, Spruit MA, van den Borne BE, Smeenk FW, Wouters EF. Whole-body versus local DXA-scan for the diagnosis of osteoporosis in COPD patients. J Osteoporos. 2010;2010:640878.

41. Yu EW, Thomas BJ, Brown JK, Finkelstein JS. Simulated increases in body fat and errors in bone mineral density measurements by DXA and QCT. J Bone Miner Res. 2012;27:119-24

\section{Ready to submit your research? Choose BMC and benefit from:}

- fast, convenient online submission

- thorough peer review by experienced researchers in your field

- rapid publication on acceptance

- support for research data, including large and complex data types

- gold Open Access which fosters wider collaboration and increased citations

- maximum visibility for your research: over $100 \mathrm{M}$ website views per year

At BMC, research is always in progress.

Learn more biomedcentral.com/submissions 